\title{
Efeitos do centeio, do trigo e da suplementação com xilanases sobre o valor nutricional de dietas e o desempenho de frangos corte
}

\author{
José Luís Teixeira de Abreu Medeiros Mourãoํㅜ, Victor Manuel Carvalho Pinheiro
}

${ }^{1}$ CECAV, Universidade de Trás-os-Montes e Alto Douro, Apartado 1013, 5000-801 Vila Real, Portugal.

RESUMO - Três experimentos foram realizados para avaliar os efeitos de dietas formuladas com 53\% de trigo ou centeio, suplementadas ou não com a enzima xilanase (0,06\%), sobre a digestibilidade de nutrientes e a energia metabolizável das dietas e sobre o desempenho e desenvolvimento do trato digestivo de frangos de corte. Como testemunha foi usada uma dieta com 53\% de milho. No primeiro experimento, as digestibilidades da matéria seca, matéria orgânica e gordura e energia metabolizável corrigida para o nitrogênio $\left(\mathrm{EMA}_{\mathrm{n}}\right)$ das dietas com centeio foram menores que daquelas com trigo (2.556 kcal/kg vs $2.842 \mathrm{kcal} / \mathrm{kg}$ ) e menores no conjunto dessas dietas que na dieta com milho ( $2.684 \mathrm{kcal} / \mathrm{kg} \mathrm{vs} 3.010 \mathrm{kcal} / \mathrm{kg})$. A digestibilidade da matéria orgânica e a $\mathrm{EMA}_{\mathrm{n}}$ das dietas com centeio também foi inferior às da dieta com trigo. A suplementação com xilanases não afetou a utilização digestiva das dietas com centeio ou com trigo. No segundo experimento, nos frangos alimentados com as dietas com centeio, o menor ganho de peso e consumo de EMA $\mathrm{n}$ e a pior conversão alimentar ocorreram entre os 8 e os 35 dias de idade. A conversão alimentar foi de 2,17 para as dietas com centeio e 1,88 para a dieta com milho. A adição de xilanases às dietas com centeio ou trigo não melhorou a conversão alimentar. Nos frangos alimentados com as dietas com centeio durante 31 dias, o duodeno-jejuno e íleo foram maiores e o rendimento de carcaça menor que nos frangos alimentados com a dieta testemunha $(71,6 \%$ vs $74,4 \%)$. As dietas com trigo não afetaram essas características. Os pesos do pâncreas e do fígado também não foram alterados pelas dietas.

Palavras-chave: conversão alimentar, digestibilidade, ganho de peso, não-amiláceos, polissacarídio, trato digestivo

\section{Effects of rye, wheat and xylanase supplementation on diet nutritive value and broiler chicken performance}

\begin{abstract}
Three trials with were conducted to evaluate the effects of diets with 53\% rye (diet C) or 53\% wheat (diet $\mathrm{T}$ ) supplemented or not with xylanase enzymes $(0.06 \%)$ on nutrient digestibility and metabolizable energy and the performance and development of the broiler chicken digestive tract. A diet with $53 \%$ corn was used as control. In trial 1 , dry matter, organic matter and apparent fat digestibilities corrected for nitrogen $\left(\mathrm{EMA}_{\mathrm{n}}\right)$ were lower in rye diets than in wheat diets (2556 kcal/kg vs $2842 \mathrm{kcal} / \mathrm{kg}$ ) and were lower in the set of these diets than in the control diet. The organic matter digestibility and $\mathrm{EMA}_{\mathrm{n}}$ in the rye were also lower than those of the wheat diets. Xylanase supplementation did not affect the digestive use of the rye or wheat diets. In trial 2, growing broiler chickens fed the rye diets showed the lowest weight gain and $\mathrm{EMA}_{\mathrm{n}}$ intake and the worst feed conversion ratio between 8 and 35 days of age. The feed conversion ratio was 2.17 with rye diets and 1.88 with the corn diet. Xylanase supplementation on rye or wheat based diets did not improve feed conversion. In trial 3, birds fed on rye diets for 31 days showed longer duodenum-jejunum and ileum and lower carcass yield than birds fed the control diet $(71.6 \%$ vs $74.4 \%)$. The wheat based diets did not affect these parameters. Pancreas and liver weights were not affected by the feeds.
\end{abstract}

Key Words: digestibility, digestive tract, feed conversion, non-starch polysaccharides, weight gain

\section{Introdução}

Os frangos de corte alimentados com dietas à base de centeio ou trigo apresentam, em geral, crescimento reduzido e conversão alimentar elevada. Esses efeitos são atribuídos à ação antinutricional dos polissacarídeos não-amiláceos (PNA) da parede celular do trigo e do centeio (Choct \& Annison, 1990). As arabinoxilanas são os PNA encontrados em maior quantidade nesses cereais (Theanther et al., 1989; Annison, 1993). A ação antinutricional está relacionada à encapsulação dos conteúdos celulares pelos PNA insolúveis presentes da parede celular, limitando o acesso das enzimas digestivas a esse conteúdo (Pettersson \& Aman, 1989), e ao aumento 
da viscosidade dos conteúdos intestinais provocada pela fração solúvel dos PNA. Esse aumento da viscosidade dificulta a ação das enzimas digestivas e o acesso dos produtos da digestão à parede do intestino delgado (Bedford et al., 1992; Mathlouthi et al., 2002b), uma vez que os teores em PNA insolúveis e solúveis do centeio são superiores aos do trigo (Smits \& Annison, 1996) e sua ação antinutricional é mais intensa (Bedford et al., 1991).

As aves alimentadas com dietas com elevados teores de PNA podem sofrer adaptações fisiológicas, como aumento do peso do pâncreas, da secreção de enzimas pancreáticas e do comprimento e da área absortiva do trato digestivo (Brenes et al., 1993; Jorgensen et al., 1996), que podem aumentar a digestão e absorção de nutrientes, compensando parcialmente os efeitos antinutricionais.

Com a finalidade de reduzir os efeitos negativos dos PNA, podem ser adicionadas enzimas às dietas, como as xilanases e outras hemicelulases, que degradam as arabinoxilanas e outros polissacarídios da parede celular em polímeros de menor tamanho, reduzindo o efeito de encapsulação e a capacidade de aumentar a viscosidade intestinal (Yasar \& Forbes, 2000; Choct et al., 2004). Desse modo, as xilanases melhoram o valor nutritivo das dietas com trigo ou centeio, o que melhora o desempenho animal (Friesen et al., 1992; Silva \& Smithard, 1997; Alam et al., 2003).

Este trabalho foi realizado com o objetivo de estudar os efeitos do trigo, do centeio e da adição de um suplemento enzimático com xilanases sobre o valor nutritivo de dietas, o desenvolvimento do trato digestivo, o rendimento de carcaça e o desempenho de frangos de corte.

\section{Material e Métodos}

Em três experimentos foram testadas cinco dietas isoproteicas que diferiam apenas quanto ao cereal utilizado (milho, trigo ou centeio) e à adição de um suplemento enzimático: dieta testemunha, com $53 \%$ de milho; dieta com $53 \%$ de trigo; dieta com $53 \%$ de trigo e $0,06 \%$ de um suplemento enzimático com xilanases; dieta com 53\% de centeio; e dieta com $53 \%$ de centeio e $0,06 \%$ de suplemento enzimático (Tabela 1). Os níveis nutricionais das dietas foram baseados na recomendação do NRC (1994). O

Tabela 1 - Composição percentual e nutricional das dietas

\begin{tabular}{|c|c|c|c|c|c|c|}
\hline & \multicolumn{6}{|c|}{ Dieta } \\
\hline & Milho & Centeio & Centeio + xilanase & Trigo & Trigo & + xilanase \\
\hline Suplemento enzimático (\% dieta) & 0,00 & 0,00 & 0,06 & 0,00 & & 0,06 \\
\hline Centeio & 0,00 & & 53,00 & & 0,00 & \\
\hline Trigo & 0,00 & & 0,00 & & 53,00 & \\
\hline Milho & 53,00 & & 0,00 & & 0,00 & \\
\hline Sal & 0,34 & & 0,34 & & 0,34 & \\
\hline Carbonato de cálcio & 0,00 & & 0,30 & & 0,30 & \\
\hline Fosfato bicálcico & 2,10 & & 1,74 & & 1,74 & \\
\hline L-lisina & 0,05 & & 0,05 & & 0,05 & \\
\hline Dl-metionina & 0,24 & & 0,26 & & 0,26 & \\
\hline $\operatorname{Aditivos}^{2}$ & 2,07 & & 2,07 & & 2,07 & \\
\hline Amido & 32,56 & & 27,70 & & 30,11 & \\
\hline Gordura bruta & 7,06 & & 7,96 & & 7,59 & \\
\hline Proteína bruta & 20,41 & & 20,92 & & 20,68 & \\
\hline PNA totais & 11,02 & & 11,98 & & 11,06 & \\
\hline PNA insolúveis & 10,08 & & 9,48 & & 9,54 & \\
\hline PNA solúveis & 0,94 & & 2,50 & & 1,52 & \\
\hline Lisina $^{3}$ & 1,23 & & 1,24 & & 1,25 & \\
\hline Metionina ${ }^{3}$ & 0,57 & & 0,57 & & 0,53 & \\
\hline Metionina + cistina $^{3}$ & 0,96 & & 0,97 & & 0,96 & \\
\hline Cálcio $^{3}$ & 0,95 & & 0,90 & & 0,93 & \\
\hline Fósforo disponível ${ }^{3}$ & 0,47 & & 0,48 & & 0,46 & \\
\hline
\end{tabular}

\footnotetext{
1 Suplemento enzimático atividade com específica mínima de $600 \mathrm{UX/g}$.
}

${ }^{2}$ Aditivos (\% dieta): cloreto de colina - 0,5; antioxidante - 0,02; anticoccidiano - 0,05; aglomerante 1 -suplemento mineral e vitaminico 0,5 contendo por kg de dieta: vit. A - 11.000 UI; vit. D3 - 2.150 UI; vit. E - 25 mg; vit. K - 1 mg; riboflavina - 5 mg; niacina - 20 mg; ácido pantotênico - 8 mg; ácido fólico - 1 mg; biotina - 0,1 mg; colina - 200 mg; vit. $B_{12}-0,012$ mg; Mn - 50 mg; Zn - 40 mg; Cu - 5 mg; Se - 0,1 mg.

${ }^{3}$ Valores totais estimados. 
suplemento enzimático tinha enzimas produzidas por Aspergillus níger, com atividade endo 1,4 beta-xylanase e outras atividades menores, como celulase, betaglucanase e amilase. A atividade específica do suplemento enzimático apresentava 600 unidades xilanase (UX) por grama e atividade estimada na dieta de $360 \mathrm{UX} / \mathrm{kg}$.

Utilizaram-se 800 pintos sexados (400 machos e 400 fêmeas) da linhagem Avian Farms, com 1 dia de idade, adquiridos num incubatório comercial e alojados em galpão experimental com condições de luz e de temperatura controladas. No primeiro dia, os pintos foram mantidos com 24 horas de luz, com redução progressiva do período diário de luz até atingir 16 horas no oitavo dia, mantendo-se depois neste valor. A temperatura ambiente foi de $33^{\circ} \mathrm{C}$ no primeiro dia de vida; depois foi progressivamente reduzida até $24{ }^{\circ} \mathrm{C}$ no início da 4 a semana de vida, mantendo-se depois neste valor. As aves foram alojadas desde o primeiro dia de vida até ao fim dos estudos em gaiolas coletivas de arame $(60 \times 50 \times 40 \mathrm{~cm})$, com exceção dos períodos em que foi determinada a digestibilidade das dietas, nos quais foram alojadas em gaiolas individuais $(25 \times 40 \times 40 \mathrm{~cm}) \mathrm{com}$ tabuleiro de recolha de excreta.

As aves foram criadas com uma dieta comercial para frangos de corte desde o primeiro dia de vida até serem utilizadas nos estudos da digestibilidade das dietas (experimento 1), do desempenho de crescimento (experimento 2) e do desenvolvimento do trato digestivo e rendimento de carcaça (experimento 3 ).

No primeiro experimento, a digestibilidade foi determinada em dois grupos de 40 aves (20 machos e 20 fêmeas), um grupo entre os 16 e os 22 dias de idade (período 1) e o outro grupo entre os 29 e os 35 dias de idade (período 2), segundo procedimentos referidos por Bourdillon et al. (1990). A digestibilidade aparente e a energia metabolizável aparente corrigida para o nitrogênio $\left(E_{n}\right)$ das dietas foram determinadas quantificando-se o consumo de dieta e a excreta produzida. O delineamento experimental foi inteiramente casualizado em arranjo fatorial $2 \times 2 \times 2+1$ (período $\times$ cereal $\times$ enzima e uma dieta testemunha), com 80 aves (repetições).

No segundo experimento, foi avaliado o desempenho de 490 pintos alojados em 70 gaiolas coletivas ( 7 pintos por gaiola; 35 gaiolas de cada sexo) entre os 8 e os 35 dias de idade. As dietas e as aves foram pesadas aos 8, 21 e 35 dias de idade e o ganho diário de peso vivo, o consumo diário de dieta e a conversão alimentar foram determinados. $\mathrm{O}$ consumo de $\mathrm{EMA}_{\mathrm{n}}$ foi calculado com base no consumo diário de dieta e nas concentrações em EMA $\mathrm{n}$ das dietas experimentais determinadas no experimento 1 . O delineamento experimental foi inteiramente casualizado em arranjo fatorial $2 \times 2+1$ (cereal $\times$ enzima e uma dieta testemunha), com catorze repetições de sete aves cada.

No terceiro experimento, para avaliação do desenvolvimento do trato digestivo e do rendimento de carcaça, foram escolhidos 70 machos e 70 fêmeas com 8 dias de idade, os quais foram criados até aos 39 dias em 20 gaiolas coletivas ( 7 pintos por gaiola; 10 gaiolas de cada sexo). Aos 39 dias as aves foram submetidas a jejum de 12 horas, pesadas e, em cada gaiola, foi escolhida para abate uma ave com o peso corporal mais próximo da média do grupo. Foram assim abatidas 2 aves de cada sexo por dieta, totalizando 20 aves. As aves foram abatidas por deslocamento cervical, sangradas e depenadas. O intestino delgado foi seccionado junto ao piloro, no divertículo de Meckel e na junção íleo-ceco-cólica, obtendo-se o duodeno-jejuno e o íleo, os quais foram medidos. Os dois sacos do ceco foram separados na base para determinação de seus comprimentos médios. O fígado, o pâncreas e o estômago vazio foram isolados e pesados e a carcaça, sem patas, cabeça, gordura abdominal e coração, foi pesada 3 horas após o abate. O rendimento de carcaça, os pesos relativos do fígado, pâncreas e estômago e os comprimentos relativos do duodeno-jejuno, íleo e ceco foram calculados em relação ao peso da ave no momento do abate. O delineamento experimental foi inteiramente casualizado em arranjo fatorial $2 \times 2+1$ (cereal $\times$ enzima e uma dieta testemunha), com quatro repetições de uma ave.

Foram analisados os teores de matéria seca, matéria orgânica, proteína bruta e gordura bruta das dietas experimentais e das excretas, segundo metodologia descrita pela AOAC (1990). O teor de amido das dietas foi determinado segundo Salomonsson et al. (1984). O teor de PNA totais, solúveis e insolúveis das dietas foi determinado pelo método colorimétrico de Englyst Cummings (1988) e a energia bruta foi quantificada usando uma bomba calorimétrica adiabática Parr (Parr Instrument Co., Moline, IL).

\section{Resultados e Discussão}

Nos resultados da digestibilidade de nutrientes e na $\mathrm{EMA}_{\mathrm{n}}$, não houve interações significativas entre $\mathrm{o}$ período e as dietas. As digestibilidades da matéria seca,

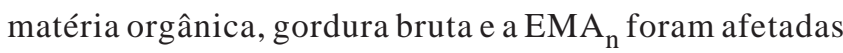
pelo período, pois foram maiores nas aves mais jovens (Período 1) (Tabela 2). Observações contrárias para a energia metabolizável foram relatadas por Wallis \& Balnave (1984) e para a digestibilidade da gordura por Ortiz et al. (1993). A diminuição da digestibilidade aparente com a idade pode 
ser devida à maior presença na excreta de matérias azotadas da urina (Jorgensen et al., 1996). O ácido úrico aumenta a quantidade de matéria seca da excreta e altera a concentração dos nutrientes, introduzindo erros por defeito nos cálculos da digestibilidade.

A incorporação de centeio ou trigo na dieta em vez do milho provocou redução acentuada da digestibilidade da matéria seca, matéria orgânica, gordura bruta e da EMA A substituição na dieta do trigo pelo centeio reduziu a digestibilidade da matéria seca, da matéria orgânica e da gordura e a EMA $A_{n}$. Esses resultados estão de acordo com observações de outros investigadores (Bedford \& Classen, 1992; Friesen et al., 1992; Huyghebaert, 1997) e confirmam que a concentração mais elevada de PNA solúveis do centeio aumenta seus efeitos antinutricionais (Bedford \& Classen, 1992; Dusel et al., 1997). A ação negativa dos PNA solúveis pode ser confirmada pela redução de 24 unidades percentuais da digestibilidade da gordura das dietas com centeio em comparação à dieta com milho, redução semelhante à observada por Friesen et al. (1992) e Silva \& Smithard (1997). Como a gordura do centeio representa cerca de $10 \%$ da gordura da dieta (valor calculado com base no teor de gordura do centeio e na sua taxa de incorporação), é possível que a encapsulação da gordura do centeio pelos PNA insolúveis tenha reduzido em cerca de 10 unidades percentuais a digestibilidade da gordura da dieta. Desse modo, a diminuição da digestibilidade da gordura das dietas com centeio também está relacionada à redução da digestibilidade da gordura de outras matérias-primas, como a soja. Os PNA solúveis do centeio teriam reduzido a capacidade de solubilização, emulsificação e absorção da gordura de todas as matériasprimas, pelo aumento da viscosidade dos conteúdos do intestino delgado e da desconjugação dos ácidos biliares (Mathlouthi et al., 2002a).

Considerando o teor de gordura nas dietas com centeio (cerca de 9\% da matéria seca), a diminuição de sua digestibilidade (24 unidades percentuais) contribuiu com cerca de 2,2 unidades para a redução de 6 unidades percentuais da digestibilidade da matéria seca destas dietas em comparação à dieta testemunha. Desse modo, a presença do centeio na dieta também reduziu as digestibilidades de outros nutrientes, como a proteína e o amido, que não foram medidas nesta pesquisa (Marquardt et al., 1994; Silva \& Smithard, 1997). A diminuição da digestibilidade da matéria orgânica e, sobretudo, da gordura das dietas à base de centeio ocasionou redução da $\mathrm{EMA}_{n}$, de modo semelhante ao observado por Danicke et al. (2000).

A adição das xilanases não melhorou significativamente qualquer característica da digestibilidade das dietas com centeio ou trigo. Esses resultados discordam dos efeitos positivos obtidos em outros experimentos com a adição de xilanases a dietas com centeio (Langhout et al., 1997; Silva \& Smithard 2002) ou com trigo (Marquardt et al., 1994),

Tabela 2 - Digestibilidade de nutrientes e energia metabolizável aparente corrigida pelo nitrogênio (EMA ) de dietas para frangos de corte em diferentes períodos de criação

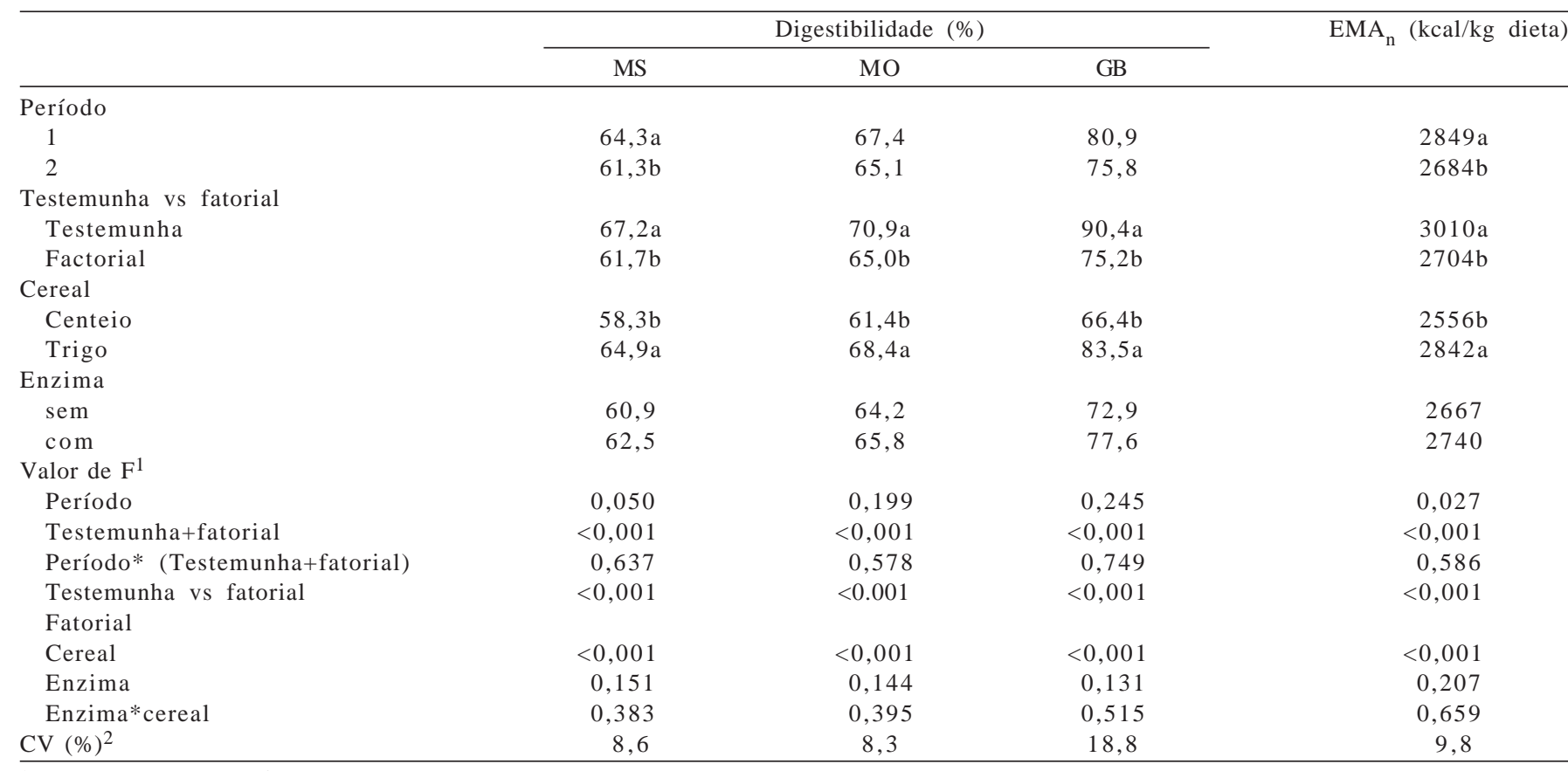

${ }^{1}$ Probabilidade do teste $\mathrm{F} .{ }^{2} \mathrm{CV}=$ coeficiente de variação.

Na mesma coluna e para o mesmo fator, médias seguidas de letras diferentes diferem $(\mathrm{P}<0,05)$. 
o que indica que $360 \mathrm{UX} / \mathrm{kg}$ de dieta são insuficientes para anular os efeitos antinutritivos dos PNA destas dietas, sobretudo aquelas com centeio.

As dietas com trigo ou centeio, em comparação à controle, afetaram sempre os parâmetros medidos no experimento de desempenho $(\mathrm{P}<0,05)$, exceto o peso corporal aos 35 dias de idade (Tabelas 3 e 4).

As dietas com centeio ou trigo foram consumidas em maior quantidade que a dieta com milho. Todavia, os frangos com dietas com centeio consumiram quantidade semelhante de dieta à ingerida por aqueles alimentados com as das dietas com trigo, os quais ingeriram menos $E M A_{n}$. Consequentemente, as aves alimentadas com as dietas com centeio apresentaram ganhos de peso e pesos corporais mais baixos e apresentaram piora na conversão alimentar em comparação às demais, confirmando os resultados descritos por Mathlouthi et al. (2002a). A superioridade do trigo em relação ao centeio para frangos em crescimento foi também observada noutros trabalhos (Friesen et al., 1992; Marquardt et al., 1994) e confirma os resultados da digestibilidade obtidos no experimento 1.

A adição de enzimas à dieta com trigo ou com centeio teve resultados positivos no consumo de EMA $_{\mathrm{n}}$ e não afetou de modo evidente o ganho de peso. Também Gonal et al. (2004) não observaram efeitos no desempenho quando adicionaram xilanases a dietas com trigo. Possivelmente, a utilização de uma dose maior de enzimas permitiria obter resultados mais evidentes, sobretudo na

Tabela 3 - Consumo de ração e de energia em frangos de corte alimentados com diferentes dietas

\begin{tabular}{|c|c|c|c|c|c|c|}
\hline & \multicolumn{3}{|c|}{ Consumo de ração (g/dia) } & \multicolumn{3}{|c|}{ Consumo EMA $_{\mathrm{n}}$ (kcal/dia) } \\
\hline & 8 a 21 dias & 21 a 35 dias & 8 a 35 dias & 8 a 21 dias & 21 a 35 dias & 8 a 35 dias \\
\hline \multicolumn{7}{|l|}{ Testemunha vs factorial } \\
\hline Testemunha & $76 \mathrm{~b}$ & $131 b$ & $104 b$ & $227 a$ & $396 a$ & $312 \mathrm{a}$ \\
\hline Factorial & $78 \mathrm{a}$ & $138 \mathrm{a}$ & $108 \mathrm{a}$ & $211 b$ & $373 b$ & $292 b$ \\
\hline \multicolumn{7}{|l|}{ Cereal } \\
\hline Centeio & 78 & 140 & 109 & $200 b$ & $359 b$ & $279 b$ \\
\hline Trigo & 78 & 136 & 107 & $221 \mathrm{a}$ & $388 a$ & $305 a$ \\
\hline \multicolumn{7}{|l|}{ Enzima } \\
\hline com & 79 & 139 & 109 & $215 a$ & $380 \mathrm{a}$ & $298 a$ \\
\hline sem & 77 & 138 & 108 & 206b & $366 b$ & $286 b$ \\
\hline \multicolumn{7}{|l|}{ Valor de $\mathrm{F}^{1}$} \\
\hline $\begin{array}{l}\text { Testemunha vs factorial } \\
\text { Factorial }\end{array}$ & 0,028 & 0,009 & 0,005 & $<0,001$ & 0,008 & 0,001 \\
\hline Cereal & 0,707 & 0,094 & 0,151 & $<0,001$ & $<0,001$ & $<0,001$ \\
\hline Enzima & 0,220 & 0,491 & 0,326 & 0,001 & 0,022 & 0,004 \\
\hline Enzima*cereal & 0,136 & 0,995 & 0,580 & 0,054 & 0,552 & 0,197 \\
\hline $\mathrm{CV}^{2}(\%)$ & 5,0 & 6,5 & 5,3 & 7,5 & 7,6 & 7,0 \\
\hline
\end{tabular}

${ }^{1}$ Probabilidade do teste $\mathrm{F} .{ }^{2} \mathrm{CV}=$ coeficiente de variação.

Na mesma colunas e para o mesmo fator, médias seguidas de letras diferentes diferem $(\mathrm{P}<0,05)$.

Tabela 4 - Ganho de peso e conversão alimentar de frangos de corte com diferentes dietas

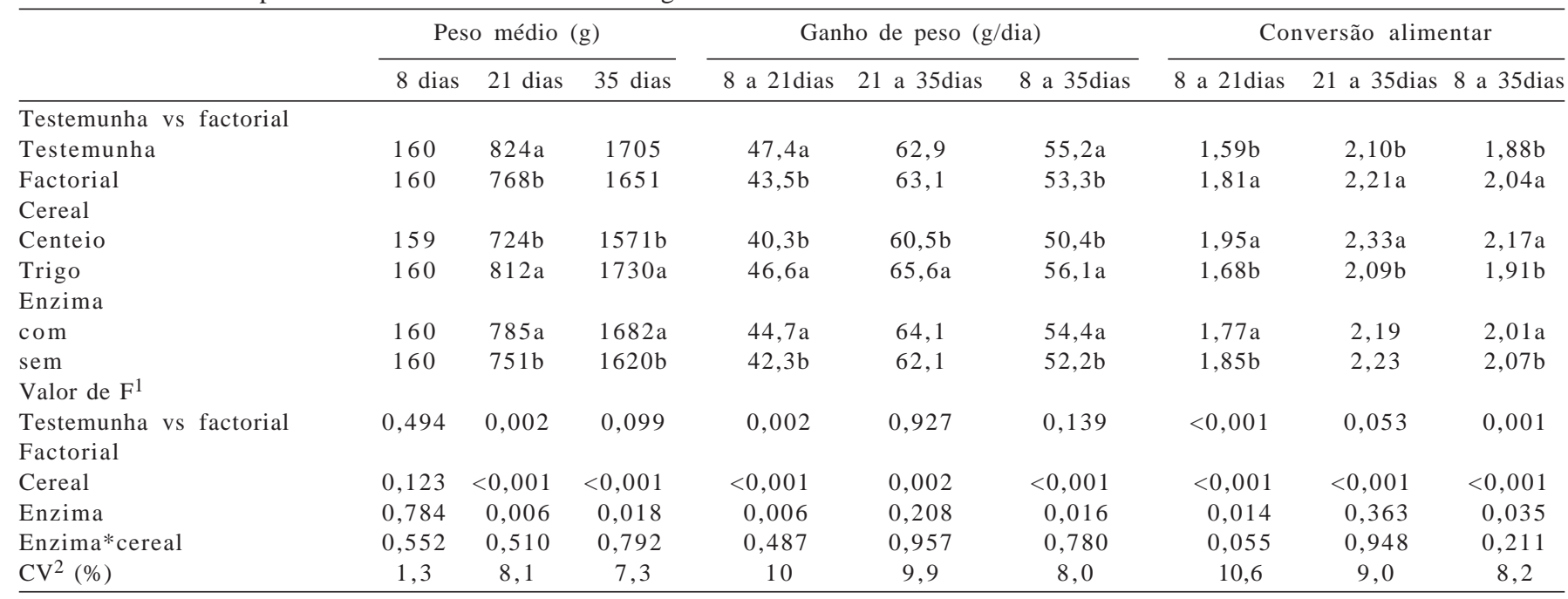

${ }^{1}$ Probabilidade do teste $\mathrm{F} .{ }^{2} \mathrm{CV}=$ coeficiente de variação.

$\mathrm{Na}$ mesma colunas e para o mesmo fator, médias seguidas de letras diferentes diferem $(\mathrm{P}<0,05)$. 
dieta com centeio. Como consequência, os frangos alimentados com as dietas com enzimas apresentaram pesos corporais menores e conversão alimentar mais alta em comparação aos alimentados com a dieta com milho. Resultados semelhantes foram observados por Antoniou \& Marquardt (1983) e Campbell et al. (1991).

A redução do crescimento e a piora na conversão alimentar nos pintos alimentados com as dietas à base de centeio ou de trigo diminuíram de intensidade com a idade. Assim, entre os 8 e os 21 dias de idade, as aves que receberam as dietas com centeio tiveram ganhos de peso 8\% inferiores aos das aves alimentadas com a dieta testemunha (43,5 g/dia vs 47,4 g/dia), enquanto, dos 21 aos 35 dias de Idade foi semelhante (63,1 g/dia vs 62,9 g/dia). Em consequência, a adição de xilanases à dieta com centeio ou trigo teve efeitos significativos na conversão alimentar apenas entre os 8 e os 21 dias. Outros estudos também indicam que os efeitos antinutricionais dos PNA e os benefícios das enzimas são mais evidentes na fase inicial de vida das aves (Dusel et al., 1998; Veldman \& Vahl, 1994). Nas aves mais velhas a produção de ácidos biliares e de enzimas digestivas aumenta (Bedford, 1995), a microflora intestinal é mais abundante, diversificada e estável (Salih et al., 1991) e a digesta contém mais umidade, o que limita os efeitos dos PNA na viscosidade do conteúdo intestinal (Salih et al., 1991; Danicke et al., 1997).

As dietas com trigo ou com centeio tenderam a aumentar o comprimento relativo do duodeno jejuno em comparação à dieta com milho (Tabela 5). As aves alimentadas com as dietas com centeio apresentaram maiores comprimentos relativos do duodeno jejuno e do íleo e pesos relativos do estômago e do pancreas em comparação aos frangos alimentados com as dietas com trigo. Outros investigadores observaram alterações semelhantes no desenvolvimento do trato digestivo quando distribuíram dietas com cevada ou trigo (Brenes et al., 1993; Svihus et al., 1997) ou com concentrações elevadas de PNA solúveis (Langhout et al., 1999). A adição de enzimas às dietas com centeio ou trigo não afetou o rendimento de carcaça nem o desenvolvimento do trato digestivo, o que poderá estar relacionado à subdosagem ou ineficiência do suplemento enzimático, uma vez que Brenes et al. (1993) e Alam et al. (2003) verificaram efeitos positivos quando adicionaram xilanases a dietas com trigo ou com arroz.

A fibra da dieta pode afetar o desenvolvimento e a atividade dos órgãos digestivos pela estimulação mecânica. Esse estímulo resulta do aumento da quantidade de dieta ingerida, que, em geral, ocorre os animais são alimentados com dietas com elevados teores de fibra (Jorgensen et al., 1996). O aumento do consumo das dietas com centeio ou com trigo registado no experimento 2 parece confirmar a estimulação mecânica. A fração solúvel da fibra pode estimular também o desenvolvimento do pâncreas, intestino delgado e ceco, conforme observaram Ikegami et al. (1990) em ratos e Veldman \& Vahl (1994) em frangos. Neste experimento, o efeito dos PNA solúveis sobre o desenvolvimento do trato digestivo das aves alimentadas com as dietas com centeio confirma as observações anteriores, uma vez que seu teor nestas dietas foi cerca de $64 \%$ mais elevado que nas dietas com trigo e $166 \%$ maior que na dieta com milho, enquanto o teor de PNA insolúveis não diferiu tão acentuadamente. Ikegami et al. (1990),

Tabela 5 - Peso vivo, rendimento de carcaça, peso dos órgãos e comprimento dos intestinos de frangos de corte com 39 dias de idade alimentados com dietas contendo trigo ou centeio e complexo enzimático

\begin{tabular}{|c|c|c|c|c|c|c|c|c|}
\hline & \multirow{2}{*}{$\begin{array}{c}\text { Peso } \\
\text { vivo (g) }\end{array}$} & \multirow{2}{*}{$\begin{array}{l}\text { Rendimento de } \\
\text { carcaça (\% PV) }\end{array}$} & \multicolumn{3}{|c|}{ Peso (g/kg PV) } & \multicolumn{3}{|c|}{ Comprimento (cm/kg PV) } \\
\hline & & & Estômago & Fígado & Pâncreas & Duodeno-jejuno & Íleo & Ceco \\
\hline \multicolumn{9}{|l|}{ Testemunha vs factorial } \\
\hline Testemunha & 2039 & 74,4 & 15,8 & 23,8 & 2,2 & 50,0 & 33,7 & 8,5 \\
\hline \multicolumn{9}{|l|}{ Cereal } \\
\hline Centeio & 1841 & $71,6 b$ & $18,8 b$ & 22,5 & $2,6 a$ & $59,4 a$ & $40,9 a$ & 9,9 \\
\hline Trigo & 1919 & $74,6 a$ & $14,9 \mathrm{a}$ & 21,5 & $2,2 b$ & $51,4 b$ & $35,1 b$ & 9,7 \\
\hline sem & 1824 & 73,6 & 15,5 & 22,1 & 2,3 & 56,1 & 37,4 & 9,5 \\
\hline \multicolumn{9}{|l|}{ Valor de $\mathrm{F}^{1}$} \\
\hline $\begin{array}{l}\text { Testemunha vs fatorial } \\
\text { Fatorial }\end{array}$ & 0,075 & 0,241 & 0,584 & 0,355 & 0,252 & 0,072 & 0,073 & 0,094 \\
\hline Cereal & 0,291 & 0,001 & 0,010 & 0,603 & 0,024 & 0,001 & 0,003 & 0,742 \\
\hline Enzima & 0,139 & 0,185 & 0,052 & 0,944 & 0,474 & 0,478 & 0,449 & 0,375 \\
\hline
\end{tabular}

${ }^{1}$ Probabilidade do teste $\mathrm{F} .{ }^{2} \mathrm{CV}=$ coeficiente de variação.

Na mesma coluna e para o mesmo fator, médias seguidas de letras diferentes diferem $(\mathrm{P}<0,05)$ 
Veldman \& Vahl (1994) e Svihus et al. (1997) sustentam que o aumento da viscosidade dos conteúdos intestinais provocada pelos PNA solúveis está na origem desses efeitos.

A adaptação do trato digestivo das aves ao consumo de dietas com teores elevados em PNA pode contribuir para a redução dos efeitos antinutricionais (Marquardt et al., 1994). O aumento do tamanho do intestino delgado observado neste experimento permitirá aumentar o tempo de permanência da dieta no trato digestivo e a superfície absortiva de nutrientes (Yasar \& Forbes, 1997). No entanto, a adaptação também pode ter consequências negativas, como a redução do rendimento de carcaça provocada pelo trato digestivo mais desenvolvido observado nas aves alimentadas com as dietas com centeio, e o aumento das perdas endógenas dos animais (Yasar \& Forbes, 1997; Danicke et al., 2000), que reduzirá a eficiência da conversão da dieta em tecido corporal.

\section{Conclusões}

Dietas com elevados teores de polissacarídios nãoamiláceos, presentes no trigo e no centeio, têm mais baixa digestibilidade dos nutrientes e promovem menor desempenho de frangos de corte. Esses efeitos são mais intensos para as dietas com centeio que para aquelas com trigo. A suplementação com 360 UX de enzima xilanase $/ \mathrm{kg}$ de dieta foi insuficiente para anular os efeitos dos polissacarídios não-amiláceos nas dietas com centeio ou com trigo. As aves adaptam-se às dietas com elevados teores de polissacarídios não-amiláceos e apresentam maior desenvolvimento do trato digestivo. Todavia, nos frangos criados até as 5 ou 6 semanas de idade, essa adaptação não permite ultrapassar os efeitos antinutritivos do centeio e piora o rendimento de carcaça.

\section{Literatura Citada}

ALAM, J.; HOWLIDER, M.A.; PRAMANIK M.A. et al. Effect of exogenous enzyme in diet on broiler performance. International Journal of Poultry Science, v.2, p.168-173, 2003.

ANNISON, G. The role of wheat NSP in broiler nutrition. Australian Journal of Agricultural Research, v.44, p.405-422, 1993.

ANTONIOU, T.C.; MARQUARDT, R.R. Utilisation of rye diets by chicks as affected by autoclave treatment, water extraction and water soaking. Poultry Science, v.62, p.91-102, 1983.

ASSOCIATION OF OFFICIAL ANALYTICAL CHEMISTS AOAC. Official methods of analysis. 13.ed. Washington, D.C.: AOAC, 1990. 1117p.

BEDFORD, M.R.; CLASSEN H.L. Reduction of intestinal viscosity through manipulation of dietary rye and pentosanase concentration is affected through changes in the carbohydrate composition of the intestinal aqueous phase and results in improved growth rate and food conversion efficiency of broiler chicks. Journal of Nutrition, v.122, p.560-569, 1992.

BEDFORD, M.R. Mechanism of action and potential environmental benefits from the use of feed enzymes. Animal Feed Science and Technology, v.53, p.145-155, 1995.

BEDFORD, M.R.; CAMPBELL G.L.; CLASSEN, H.L. The effect of pelleting, salt and pentosanase on the viscosity of intestinal contents and the performance of broiler fed rye. Poultry Science, v.70, p.1571-1577, 1991.

BEDFORD, R.M.; PATIENCE, J.F.; CLASSEN, H.L. et al. The effect of dietary enzyme supplementation on rye and barley based diets on digestion and subsequent performance in weaning pigs. Canadian Journal of Animal Science, v.72, p.97-105, 1992.

BOURDILLON, A.; CARRE, B.; CONAN, L. et al. European Reference Method for the in vivo determination of ME in poultry: Reproducibility, effect of food intake and compression with predicted values. British Poultry Science, v.31, p.567-576, 1990.

BRENES, A.; SMITH, M.; GUENTER, W. et al. Effect of enzyme supplementation on the performance and digestive tract size of broiler chicks fed wheat- and barley-based diets. Poultry Science, v.72, p.1731-1739, 1993.

CAMPBELL, H.L.; TEIGTE, D.A.; CLASSEN, H.L. Genotypic and environmental differences in dietary pentosanes fed to broiler chicks with pentosanase suplementation. Canadian Journal of Animal Science, v.71, p.1241-1247, 1991.

CHOCT, M.; ANNISON, G. Anti-nutritive activity of wheat pentosans in broiler diets. British Poultry Science, v.31, p.811- 821, 1990

CHOCT, M.; KOCHER, A.; WATERS, D.L. et al. A comparison of three xylanases on the nutritive value of two wheats for broiler chickens. British Journal of Nutrition, v.92, p.53-61, 2004.

DANICKE, S.; SIMON, O.; JEROCH, H. et al. Interactions between dietary fat type and xylanase supplementation when rye-based diets are fed to broiler chickens. 1. Physicochemical chyme features. British Poultry Science, v.38, p.537-545, 1997.

DANICKE, S.; JEROCH, H.; BOTTCHER, W. et al. Interactions between dietary fat type and enzyme supplementation in broiler diets with high pentosan contents: effects on precaecal and total tract digestibility of fatty acids, metabolizability of gross energy, digesta viscosity and weights of small intestine. Animal Feed Science and Technology, v.84, p.279-294, 2000.

DUSEL, G.; KLUGE H.; GLÄSER, K. et al. An investigation into the variability of extract viscosity of wheat - relationship with the content of non-starch-polysaccharide fractions and metabolisable energy for broiler chickens. Archiv für Tierernährung, v.50, p.121-135, 1997.

DUSEL, G.; KLUGE, H.; JEROCH, H. Xylanase supplementation of wheat-based rations for broilers: influence of wheat characteristics. Journal of Applied Poultry Science Research, v.7, p.119-131, 1998.

ENGLYST, H.N.; CUMMINGS, J.H. Improved method for measurement of dietary fiber as non-starch polysaccharides in plant foods. Journal Association of Official Analytical Chemists, v.71, n.4, p.808-814, 1988.

FRIESEN, O.D.; GUENTER, W.; MARQUARDT, R.R. et al. The effect of enzyme supplementation on the apparent metabolise energy and nutrient digestibilities of wheat, barley, oats and rye for the young broiler chicks. Poultry Science, v.71, p.1710-1721, 1992.

GONAL, M.; YASAR, S.; FORBES, J.M. Performance and some digesta parameters of broiler chickens given low or high viscosity wheat-based diets with or without enzyme supplementation. 
Turk Journal Veterinary Animal Science, v.28, p.323-327, 2004.

HUYGHEBAERT, G. The effect of a wheat-fat-interaction on the efficacy of a multi-enzyme preparation in broiler chickens. Animal Feed Science and Technology, v.68, p.55-66, 1997.

IKEGAMI, S.; TSUCHIHASHI, F.; HARADA, H. et al. Effect of viscous indigestible polysaccharides on pancreatic-biliary secretion and digestive organs in rats. Journal of Nutrition, v.120, p.353 -360, 1990 .

JORGENSEN, H.; ZHAO, X.; KNUDSEN, K.E. et al. The influence of dietary fibre source and level on the development of the gastrointestinal tract, digestibility and energy metabolism in broiler chickens. British Journal of Nutrition, v.75, p.379-395, 1996 .

LANGHOUT, D.J.; SCHUTTE J.B.; VAN LEEUWEN P. et al. Effect of dietary high- and low-methylated citrus pectin on activity of the ileal microflora and morphology of the small intestinal wall of broiler chicks. British Poultry Science, v.40, p.340-347, 1999.

LANGHOUT, D.J.; SCHUTTE, J.B.; GEERSE, C. et al. Effects on chick performance and nutrient digestibility of an endo-xylanase added to a wheat- and rye-based diet in relation to fat source. British Poultry Science, v.38, p.557-563, 1997.

MARQUARDT, R.R.; BOROS, D.; GUENTER, W. et al. The nutritive value of barley, rye, wheat and corn for young chicks as affected by use of a Trichoderma reesei enzyme preparation. Animal Feed Science and Technology, v.45, p.363-378, 1994.

MATHLOUTHI, N.; LALLÈS, J.P.; LEPERCQ, P. et al. Xylanase and $ß$-glucanase supplementation improve conjugated bile acid fraction in intestinal contents and increase villus size of small intestine wall in broiler chickens fed a rye-based diet. Journal of Animal Science, v.80, p.2773-2779, 2002a.

MATHLOUTHI, N.; SAULNIER, L.; QUEMENER, B. et al. Xylanase, beta-glucanase, and other side enzymatic activities have greater effects on the viscosity of several feedstuffs than xylanase and beta-glucanase used alone or in combination. Journal of Agricultural and Food Chemistry, v.50, n.18, p.5121-5127, 2002b.

NATIONAL RESEARCH COUNCIL - NRC. Nutrient requirements of poultry. 9.ed. Washington, D.C.: National Academy Press, 1994. p.155.

ORTIZ, I.T.; REBOLE, A.; RODRIGUEZ, M.L. et al. Effect of chicken age on the nutritive value of diets with graded additions of full-fat sunflower seed. British Poultry Science, v.39, p.530-535, 1993.
PETTERSSON, D.; AMAN, P. Enzyme supplementation of a poultry diet containing rye and wheat. British Journal of Nutrition, v.62, p139 -149, 1989.

SALIH, M.E.; CLASSEN, H.L.; CAMPBELL, G.L. Response of chickens fed on hull-less barley to dietary b-glucanase at different ages. Animal Feed Science and Technology, v.33, p.139-149, 1991.

SALOMONSSON, A.C.; THEANDER, O.; WESTERLUND, E. Chemical characterization of some swedish cereal whole meal and bran fractions. Swedish Journal of Agricultural Research, v.14, p.111-117, 1984.

SILVA, S.S.; SMITHARD, R.R. Digestion of protein, fat and energy in rye-based broiler diets is improved by the addition of exogenous xylanase and protease. British Poultry Science, v.38, p.S38-S39, 1997.

SILVA, S.S.; SMITHARD, R.R. Effect of enzyme supplementation of a rye-based diet on xylanase activity in the small intestine of broilers, on intestinal crypt cell proliferation and on nutrient digestibility and growth performance of the birds. British Poultry Science, v.43, p.274-282, 2002.

SMITS, C.H.; ANNISON, G.. Non-starch polysaccharides in broiler nutrition - towards a physiologically valid approach to their determination. World's Poultry Science Journal, v.52, p.203-221, 1996.

SVIHUS, B.; NEWMAN, R.K.; NEWMAN, C.W. Effect of soaking, germination, and enzyme treatment of whole barley on nutritional value and digestive tract parameters of broiler chickens. British Poultry Science, v.38, p.390-396. 1997.

THEANTHER, O.; WESTERLUND, E.; AMAN, P. et al. Plant cell wall and monogastric diets. Animal Feed Science and Technology, v.23, p.205-225, 1989.

VELDMAN, A.; VAHL, H.A. Xylanase in broiler diets with differences in characteristics and content of wheat. British Poultry Science, v.35, p.537-550, 1994.

WALLIS, I.R.; BALNAVE, D. The influence of environmental temperature, age and sex on the digestibility of aminoacids in growing broiler chickens. British Poultry Science, v.25 p.401-407, 1984

YASAR, S.; FORBES, J.M. Effects of wetting and enzyme supplementation of wheat-based foods on performance and gut responses of broiler chickens. British Poultry Science, v.38, p.S43-S44, 1997 (suppl.).

YASAR, S; FORBES, J.M. Enzyme supplementation of dry and wet wheat-based feeds for broiler chickens: performance and gut responses. British Journal of Nutrition, v.84, p.297-307, 2000 